\title{
Investigation of the individual and feminist cultural memory in the epistolary biography of Anadibai Joshee by Meera Kosambi
}

\author{
Niranjana ${ }^{1}$, Dr. G. Bhuvaneswari ${ }^{2}$
}

\author{
${ }^{1} \mathrm{PhD}$ Scholar, Vellore Institute of Technology, Chennai, India \\ ${ }^{2}$ Assistant Professor Senior, Vellore Institute of Technology, Chennai, India
}

Received: 18 Sept 2020; Received in revised form: 17 Nov 2020; Accepted: 22 Nov 2020; Available online: 07 Dec 2020

(C)2020 The Author(s). Published by Infogain Publication. This is an open access article under the CC BY license

(https://creativecommons.org/licenses/by/4.0/).

\begin{abstract}
Memory studies is an interdisciplinary field and Literature serves as one of the media of cultural memory as history, art and other forms of media", said Astrid Erll. According to Maurice Halbwachs, there exists no individual memory but a collective memory. Our memory is the product of the personal individual experiences informed by societal practices. This study involves investigating the letters of Anadibai Joshee, the first woman doctor of India to understand the role of cultural memory in the sensitization of the female gender during her times. "Fragmented Feminism: Life and letters of Anadibai Joshee" written by the sociologist Meera Kosambi is an epistolary biographical fiction and it acts as the site of memory to understand the socio-political and cultural impact on the upper class Hindu brahmin women during the nineteenth century. Also, the memories and reflections of Anadibai Joshee stand as a medium to understand the sexist and Gender biases during her time.
\end{abstract}

Keywords-Memory, culture, epistolary, feminism, gender.

\section{INTRODUCTION}

\section{Memory Studies}

Memory studies have emerged as the tool for exploring, remembering, and analyzing the past with the help of literature, art, history, archaeology, and media as the sites of memory. It is an interdisciplinary field and Literature serves as the symbolic representation of the cultural memory as history, art, and other forms of media. Astrid Erll. (Erll, 145)

'Memory proceeds selectively. From the abundance of events, processes, persons, and media of the past, it is only possible to remember very few elements. As Ernst Cassirer noted, every act of remembering is a 'creative and constructive process. It is not enough to pick up isolated data of our experience; we must recollect them, we must organize and synthesize them, and assemble them into a focus of thought' (Cassirer 1944, 51). The selected elements must be formed in a particular manner to become an object of memory. Such formative processes can be detected in many media and practices of memory; they are also - and primarily - found in literature'

There exists a clear parallel between memory and cultural artifacts or in other words, literature, arts, history, and media are symbolic representations of memory. According to Maurice Halbwachs, there exists no individual memory but a collective memory. Our memory is the product of the individual experiences informed by the societal practices deriving its idea from Wolfgang Iser's phenomenological approach towards the reading process, wherein he proposed that the attitudes and reaction of the reader to the text or the pre-conceived notions of the reader are the experiences which form the basis of interpreting/ reading the text. Therefore, reading/decoding the memories implies the reconstruction of the past with present attitudes and beliefs. (Erll, 17)

'Halbwachs makes a sharp distinction between history and memory, which he sees as two mutually exclusive forms of reference to the past. Right at the beginning of his comparison of 'lived' memory and 
'written' history in La memoir collective, Halbwachs emphasizes that 'general history starts only when tradition ends and the social memory is fading or breaking up' For Halbwachs, history deals with the past. Collective memory, in contrast, is oriented towards the needs and interests of the group in the present, and thus proceeds in an extremely selective and reconstructive manner. Along the way, what is remembered can become distorted and shifted to such an extent that the result is closer to fiction than to a past reality. Memory thus does not provide a faithful reproduction of the past - indeed, quite the opposite is true: 'A remembrance is in very large measure a reconstruction of the past achieved with data borrowed from the present, a reconstruction prepared, furthermore, by reconstructions of earlier periods wherein past images had already been altered' (ibid., 68). This already points to what half a century later, within poststructuralist discussions, will be called 'the construction of reality.",

Maurice's ideas overlap with Jean Baudrillard's concept of simulacra and simulation where there is no reality but altered realities (hyper realities) That is, the present interpretations of the past are reconstructed by the present or in other words shaped by the present. (Erll, 105)

' I use the term 'collective-autobiographical memory' to refer to the collective remembering of a shared past. Psychological studies of the individual autobiographical memory emphasize its dynamic, creative, and narrative nature, as well as its identity-creating functions. On the social and media level, too, 'autobiographical' versions of the past are highly constructive and fulfill the function of self-description ('our past, our identity'). Through collective-autobiographical acts of memory, group identities are created, the experience of time is culturally shaped, and shared systems of values and norms are established. Collective-autobiographical remembering is often described with terms such as 'remembrance' or 'commemoration'. The Assmanns' 'Cultural Memory' with its normative and formative myths and the 'communicative memory' with its shared fabrication of narratives about the recent past are typical examples of this memory system. Nora's lieux de mémoire, on the other hand, are located below the level of autobiographical narrativization; they represent a kind of 'collective-episodic memory' which is not transformed into coherent stories (or 'master narratives'), but is instead condensed into a multitude of particular 'sites of memory'.

It is clearly understood that there exists no individual memory but a collective memory. Every individual's memory is shaped by the multiple frameworks that are part of his/her social interaction. (Erll, 154)

ISSN: 2456-7620
'Literature fills a niche in memory culture, because like arguably no other symbol system, it is characterized by its ability - and indeed tendency - to refer to the forgotten and repressed as well as the unnoticed, unconscious, and unintentional aspects of our dealings with the past. It is thus already on the level of mimesis1, through the references that constitute the textual repertoire, that literature actualizes elements which previously were not - or could not be perceived, articulated, and remembered in the social sphere. Through the operation of selection, literature can create new, surprising, and otherwise inaccessible archives of cultural memory: Elements from various memory systems and things remembered and forgotten by different groups are brought together in the literary text. Structure of the literary text, every element has its place and thus also gains its meaning. 'This passage from the paradigmatic to the syntagmatic constitutes the transition from mimesis 1 to mimesis2. It is the work of the configurating activity' (66). It is also the passage into fiction; with their configuration into a story, the ontological status of the chosen elements changes: 'With mimesis2 opens the kingdom of the as if' (64). Literary mimesis is therefore not simply a representation of reality; in fact, configuration is an active, constructive process, a creation of reality, so that the term 'poiesis' seems a more fitting description (66). Ricoeur emphasizes Not only emplotment is to be counted among the configurating activities taking place on the level on mimesis2. Other literary forms also contribute in great measure to the creation of fictional memory narratives: Narrative voice, perspective, and focalization, literary chronotopoi (time-space combinations), metaphors, and symbols, to name just some particularly significant examples, are strategies involved in the performance, or staging, of cultural memory in literature .'

Ricoeur's classification can be very helpful in understanding the representation of memory in literature and it demonstrates how literature replicates or act as a parallel for the memory system where the new experiences alter the existing experiences and present as new schemata for future experiences. In the same way, the configured literary narrative act as the framework for further narratives. (Fivush, 149)

'How individuals recount their histories-what they emphasize and omit, their stance as protagonists or victims, the relationship the story establishes between teller and audience - all shape what individuals can claim of their own lives. Personal stories are not merely a way of telling someone (or oneself) about one's life; they are the means by which identities may be fashioned. Through examining autobiographical narratives, we gain access to individuals' construction of their own identity. What individuals choose 
to tell, what information they select to report, provides converging evidence of how individuals conceptualize their selves.'

Research in developmental psychology suggests that the stories we chose to tell determine our identity in the chosen context and also there exist multiple evolving identities for an individual.

This study attempts to uncover firstly, the intersection of multiple frameworks in Anandibai's letters to remember/re-construct the past and Secondly, how the episodic memories take shape in her letters which reflect the position/condition of women in colonial India.

\section{ANALYSIS}

Our memories do not remember every experience in our life. There is actual configuration happening in the construction of the narrative which pre-figures the experiences which are to be represented. The social, cultural, and political frameworks that operate at the present determines the experiences that are represented in the narratives. (Erll, 145)

'Memory proceeds selectively. From the abundance of events, processes, persons, and media of the past, it is only possible to remember very few elements. As Ernst Cassirer noted, every act of remembering is a 'creative and constructive process. It is not enough to pick up isolated data of our experience; we must recollect them, we must organize and synthesize them, and assemble them into a focus of thought' (Cassirer 1944, 51). The selected elements must be formed in a particular manner to become an object of memory.'

The expression of physical abuse gains representation in Anandibai's letter demonstrates the operation of the patriarchal structure at play. The patriarchal structure here not only refers to a male-dominated structure, but any form of control exercised over women. The term, 'Patriarchy' is used as an umbrella term to denote all forms of power and control over women. Anandibai explicitly talks about a great deal on the physical abuse exercised over and the agony of her memories in her letters.

'Hitting', 'Throwing chairs', 'Flinging books', 'Threatening' 'Throwing stones, charcoals', and 'beatings' are the actions that describe the performativity of Masculinity hubris over Anandibai. Here the term 'Masculinity' is used in a similar sense as 'Patriarchy' that is, the role that is being performed is referred not the actual sex.

The mention of low esteem for other cultures especially Islamic cultures, self-culture pride was pre- dominant among upper-class Hindus and reflects the collective cultural belief for lower castes. Almost in all her letters describing Indian Culture and the condition of women, the convergence of individual experiences with cultural frameworks operating at the time is evident from the form in which it takes shape. (Kosambi, 47)

'We have no polygamy to speak if. Though there is no social or religious restriction on a man to marry as many times as he likes, yet the middle-class men do not take more than one wife for fear that their coffer would be empty and they would run into debt from which they would never be extricated if once got in to. The chiefs, princes, and generally higher classes have more than one wife. The Nizam of Hyderabad had 300 wives and the sultan of Turkey in the west has as many now. Our people, if they at all take more than one wife, marry for the sake of sons if they do not have any by the first or second wife. So, you see how fond we are of sons socially and religiously. The heavens are open to the man who has a son but not otherwise. If a man dies without a son, his head is covered when his corpse is taken to the burning ground. There are many rites and funeral ceremonies which none, but a son is eligible to perform and without which the dead man is supposed to be damned and hurled down to Hell.'

The disparity of the structure of marriage which favors men over women and Anandibai's silent remorse for it displays the raising of feminist' consciousness. When Anandibai talks about India, her narratives exhibit the influence of the religious, cultural, and social structures which operate in the life of women. The episodic memory from the life of Anandibai Joshee is represented in her letters. Her experiences gain agency in our words. Our human memory is shaped through different frameworks such as religion, society, culture, and literature. The interplay of patriarchy, culture, imperialistic attitudes and religion in shaping the consciousness of Anandibai is evident from her letters. Her letters inform the dominant cultural practices of the past.

Therefore, the letters are the reflection of the shared vision of the people belongs to her generation and collective memories of the marginalized Hindu women community which gets expression in her letters. This is the representation of collective-episodic memory as Nora puts it

Her correspondences with her husband highlighted the intersection of two cultures (American and Indian) concerning the institution of marriage and the associated roles and responsibilities that comes with it. She is performing the role of her gender repeatedly which is clear from the use of the words, 'forgiveness', 'supervision', 
'disloyalty ', and 'misunderstood'. By doing so, she confirms her role as 'Other' in the sight of Patriarchy.

Her letters configure the feminist cultural memory of Colonial India highlighting the experience and position of women.

\section{CONCLUSION}

The narrative self and identity of an individual gain agency in life writing. Similarly, Anandibai's identity as an Indian woman emerges in her narratives and she foregrounds the identity of Gender in recounting events and experiences. Although individuals remain female or male across situations and development, how gender identity is understood, and how salient gender is as an aspect of identity, will vary both situationally and developmentally. (Fivush, 151) In Anandibai's letters, gender being salient highlights the social and cultural practices affecting women over men becomes evident. Also, the context and the interpersonal relationship with her husband and Mrs. Carpenter contributes to her developing identity. Her expression of her traumatic experiences substantiates her autonoetic awareness, which subsequently acts as evidence of the position of women during her times.

\section{REFERENCES}

[1] Erll, Astrid. "Memory in Culture Palgrave Macmillan memory Studies." Palgrave Macmillan, 2016

[2] Baudrillard, Jane. "Simulacra and Simulation." University of Michigan Press, 1994

[3] Iser, Wolfgang. "Reading Process as Phenomenological approach"

[4] During, Simon. "The Cultural Studies Reader." Taylor and Francis, 2007

[5] Butler, Judith, "Gender Trouble.” Routledge Classics, 2016

[6] Foucault, Michael. "The Archaeology of Knowledge: And the discourse on Language." Vintage, 1982

[7] Parui, A. (2016). "For the life of him he could not remember': Post-war Memory, Mourning and Masculinity Crisis in Katherine Mansfield's 'The Fly'. In W. Martin (Author) \& C. Hanson \& G. Kimber (Eds.), Katherine Mansfield and Psychology (pp. 113-124). Edinburgh University Press.

[8] Kosambi, Meera. 'A Fragmented Feminism THE LIFE AND LETTERS OF ANANDIBAI JOSHEE'. Edited by Ram Ramaswamy, Madhavi Kolhatkar and Aban Mukherji. Routledge, 29 August 2019.

[9] Chakravarti, Uma. 'Gendering Caste: Through a Feminist Lens.' SAGE Publications Pvt. Ltd, 15 October 2018.

[10] John, E, Mary. 'Women's studies in India: A Reader.' Penguin India 25 August 2008.
[11] Haden, Catherine, Fivush, Robyn. 'Autobiographical memory and the construction of a narrative self.' Psychology Press; 1 edition (14 May 2003) 